\title{
Prenatal Allergic Sensitization to Helminth Antigens in Offspring of Parasite-infected Mothers
}

\author{
Gary J. WeIL, Laboratory of Parasitic Diseases, National Institutes \\ of Health, Bethesda, Maryland 20205 \\ Rabia Hussain, Laboratory of Parasitic Diseases, National Institutes \\ of Health, Bethesda, Maryland 20205 \\ V. Kumaraswami, Tuberculosis Research Centre, Madras, India \\ SRIRAM P. TRIPAThy, Tuberculosis Research Centre, Madras, India \\ K. S. Phillips, Madras Medical College, and the Institute of \\ Obstetrics and Gynecology, Madras, India \\ Eric A. OtTESEN, Laboratory of Parasitic Diseases, and Laboratory of Clinical \\ Investigation, National Institutes of Health, Bethesda, Maryland 20205
}

\begin{abstract}
A B S T R A C T Total and filaria-specific immunoglobulin $\mathrm{E}$ (IgE) levels were studied in cord blood from infants born in Madras, India, where filariasis and intestinal helminth infections are highly endemic. Increased total IgE levels were observed in $82 \%$ of 57 cord sera tested (geometric mean $12.6 \mathrm{ng} / \mathrm{ml}$; range $1-1,900 \mathrm{ng} / \mathrm{ml}) .33$ of these sera also contained $\mathrm{IgE}$ antibodies specific for filarial antigens as determined by solid-phase radioimmunoassay. Comparison of ratios of filaria-specific IgE to total $\operatorname{IgE}$ in paired maternal and cord sera suggested that cord blood IgE was derived from the fetus in most cases and not from transplacental antibody transfer. Our results suggest that prenatal allergic sensitization to helminth parasites occurs in the tropics. Such sensitization may contribute to the heterogeneity in host immune response and disease expression noted in filariasis and other helminth infections.
\end{abstract}

\section{INTRODUCTION}

The human fetus develops immunoglobulin $\mathrm{E}$ (IgE)producing $B$ cells early in gestation (1) and is presumably capable of producing IgE antibodies in response

\footnotetext{
Address correspondence regarding the manuscript to $\mathrm{Dr}$ G. J. Weil, at his new address, Infectious Diseases Division, The Jewish Hospital of St. Louis, St. Louis, MO 63110.

Address reprint requests to Dr. E. A. Ottesen, National Institutes of Health, Bethesda, MD 20205 or Dr. S. P. Tripathy, Tuberculosis Research Centre, Madras, India 600031.

Received for publication 12 February 1982 and in revised form 17 January 1983.
}

to appropriate antigenic stimuli in a manner analogous to the well-recognized IgM responses that are observed in various prenatal infections (2). Although several cases of allergic sensitization in the newborn have been reported $(3,4)$, the extremely low values for cord blood IgE reported in series from the United States and Europe suggest that prenatal IgE responses are quite unusual in the developed world (4-8). In this study, we have attempted to demonstrate prenatal allergic sensitization by measuring $\mathrm{IgE}$ in cord blood of babies born to mothers with parasitic helminth infection. Helminth infections are known to stimulate IgE production (9) and we reasoned that the offspring of parasite-infected mothers might be exposed to parasite antigens in utero; circulating parasite antigens are frequently demonstrable in the blood of patients with tissue helminth infections (10), and in the case of filariasis, actual parasitemia is common. Our results indicate that increased levels of cord blood IgE are frequently observed in the setting of maternal helminth infection. They further suggest that in most cases, increased cord blood IgE resulted from fetal immune responses to parasite antigens and not transplacental transfer of IgE from mother to fetus.

\section{METHODS}

Serum samples. Paired cord and maternal blood samples were collected at Government Maternity Hospital in Madras, India. Patients at that hospital have a high prevalence of infection with the filarial parasite Wuchereria bancroft $i$ and a very high prevalence of mixed intestinal helminth infection. Normal term vaginal deliveries occurring while two or 
more of the investigators were present in the delivery suite were accepted into the study without further selection except that the first 41 blood pairs were collected from deliveries occurring between 9 p.m. and 2 a.m. to increase the chance of detecting the nocturnally periodic microfilariae in cord blood. For the last 16 pairs collected, cord blood was obtained from daytime deliveries and maternal blood was collected later that same day at 11 p.m. The different patterns of collecting blood specimens did not affect the results obtained. Cord and maternal blood samples were collected by the investigators in different sized tubes to minimize the chance of mislabeling the specimens. Cord blood was collected before delivery of the placenta. Sera were stored in liquid nitrogen or at $-70^{\circ} \mathrm{C}$ until the time of assay. Microfilaremia was assessed by membrane (Nucleopore Corp., Pleasanton, CA) filtration of $1 \mathrm{ml}$ of heparinized cord and maternal blood (11).

Serologic methods. Total IgM and IgA levels in cord sera were measured by radial immunodiffusion with a lower limit of sensitivity of $0.1 \mathrm{mg} / \mathrm{ml}$ (low level IgM and IgA kits, Miles Laboratories, Inc., Research Products Div., Elkhart, IN).

Total serum IgE was measured with a direct solid-phase radioimmunoassay (RIA) (paper radioimmunosorbent test [PRIST], ${ }^{1}$ Pharmacia Fine Chemicals, Piscataway, NJ). Cord sera were tested undiluted and all values $>20 \mathrm{ng} / \mathrm{ml}$ were repeated.

Filaria-specific IgG and IgM were measured by enzymelinked immunosorbent assay. Since $W$. bancrofti cannot be maintained in laboratory animals, the closely related human filarial parasite Brugia malayi was used as the source of filarial antigens (12).

Filaria-specific IgE was measured by direct solid-phase RIA using adult $B$. malay $i$ antigens as previously described $(13,14)$. Briefly, sera were preabsorbed with $1 \%$ Sepharose 4B (Pharmacia Fine Chemicals) overnight, then incubated in plastic tubes with $B$. malayi antigens covalently bound to $\mathrm{CNBr}$-activated Sepharose $4 \mathrm{~B}$ in radioallergosorbent test (RAST) buffer (phosphate-buffered saline, pH. 7.4, with $0.4 \%$ Tween $20,0.2 \%$ bovine serum albumin, and $0.1 \%$ sodium azide) for $15 \mathrm{~h}$ at room temperature with rotation. After three washes with RAST buffer, ${ }^{125}$ I-labeled, affinitypurified goat anti-human IgE was added to the tubes and incubated as above. The beads were washed four times with RAST buffer and bound radioactivity was measured with a gamma counter. The amount of filaria-specific IgE was derived from a standard curve run with each assay using a reference filariasis serum pool containing a known amount of filaria-specific IgE, determined by depletion analysis as previously described (13). We have previously found that the $B$. malayi sorbent does not bind irrelevant IgE nonspecifically (unpublished observations) and that parasite-specific IgG does not significantly interfere with the assay (14). The sensitivity of the assay varied from 0.2 to $0.4 \mathrm{ng} / \mathrm{ml}$. Cord sera were tested at a 1:2 dilution and all positive tests were repeated. To test for nonspecific reactivity of cord sera, six cord sera from term infants born in Bethesda, MD, were tested for total IgE by PRIST and for filaria-specific IgE by solid-phase RIA. All of these sera contained $<1.2 \mathrm{ng} / \mathrm{ml}$ of total IgE and no detectable filaria-specific IgE.

Antigen-induced histamine release was performed with cord blood leukocytes and B. malayi adult antigens (15). Cord blood leukocytes were obtained by gravity sedimentation of cord blood mixed 1:2 with a solution of $6 \%$ dextran

\footnotetext{
${ }^{1}$ Abbreviations used in this paper: PRIST, paper radioimmunosorbent test; RAST, radioallergosorbent test.
}

and $0.1 \%$ EDTA in normal saline. After three washes in Tyrode's solution lacking $\mathrm{Ca}^{++}$and $\mathrm{Mg}^{++}$, the cells were aliquoted into tubes to which varying concentrations of antigen were added along with $\mathrm{Ca}^{++}\left(1.8 \times 10^{-6} \mathrm{M} /\right.$ liter $\left.\mathrm{CaCl}_{2}\right)$ and $\mathrm{Mg}^{++}\left(1.0 \times 10^{-6} \mathrm{M} /\right.$ liter $\left.\mathrm{MgCl}_{2}\right)$ ions. The total reaction volume was $0.5 \mathrm{ml}$. After incubation for $30 \mathrm{~min}$ at $37^{\circ} \mathrm{C}$, supernatants were collected, frozen, and later assayed for histamine by a radioenzymatic technique (16). The histamine released during basophil degranulation was compared with the total histamine content of the cells, determined by freeze-thawing other aliquots. Spontaneous histamine release in the absence of antigen was $11.5 \pm 3.9 \%(\mathrm{SE})(n=4)$. Results were expressed as the percentage of histamine release: \% histamine release $=100$ (experimental - spontaneous/total - spontaneous)

\section{RESULTS}

13 of the 57 mothers had circulating W. bancrofti microfilariae, but none had elephantiasis. Microfilariae were absent from all cord blood samples.

Total serum IgE values are presented in Fig. 1. Maternal IgE values were very high, as expected in a population with a high prevalence of helminth infection. IgE levels in cord sera were also high in comparison with values reported for offspring of nonatopic mothers (upper limit of normal, $3 \mathrm{ng} / \mathrm{ml}$ ) (4). In fact, only 2 of 301 cord IgE values (PRIST) previously reported exceeded the geometric mean IgE value observed in this series (4-8).

All maternal sera had high levels of filaria-specific IgE (Fig. 2). 33 of 57 cord sera had detectable filariaspecific IgE. Data from 22 cord sera with $>3 \mathrm{ng} / \mathrm{ml}$ filaria-specific IgE were subjected to further analysis in an attempt to establish the origin of the $\operatorname{IgE}$ in these sera (Fig. 3). If one assumes that cord blood IgE was not derived from the fetus but from transplacental passage of blood during labor, ratios of filaria-specific IgE to total IgE in paired cord and maternal sera should be equal; this result was observed in 8 of 22 cases. However, in 14 of 22 serum pairs, the amount of filaria-specific IgE in cord blood was greater (fourfold or more) than that predicted by the transplacental leakage hypothesis. Such results, suggesting prenatal allergic sensitization to filarial antigens, were observed in 5 of 13 cord sera from microfilaremic mothers and 9 of 44 cord sera from amicrofilaremic mothers (difference not significant by chi-square analysis).

In vitro leukocyte histamine release studies were performed with cord leukocytes from four infants to assess the presence of cell-bound filaria-specific IgE. The results obtained were consistent with the serum filaria-specific IgE values determined by RIA (Fig. 4).

Total IgM and IgA determinations were performed for cord sera to further assess the possibility that cord samples were contaminated by maternal blood as these isotypes, like IgE, have been reported not to cross the placenta (2). Elevated $(>0.2 \mathrm{mg} / \mathrm{ml})$ IgM levels were 


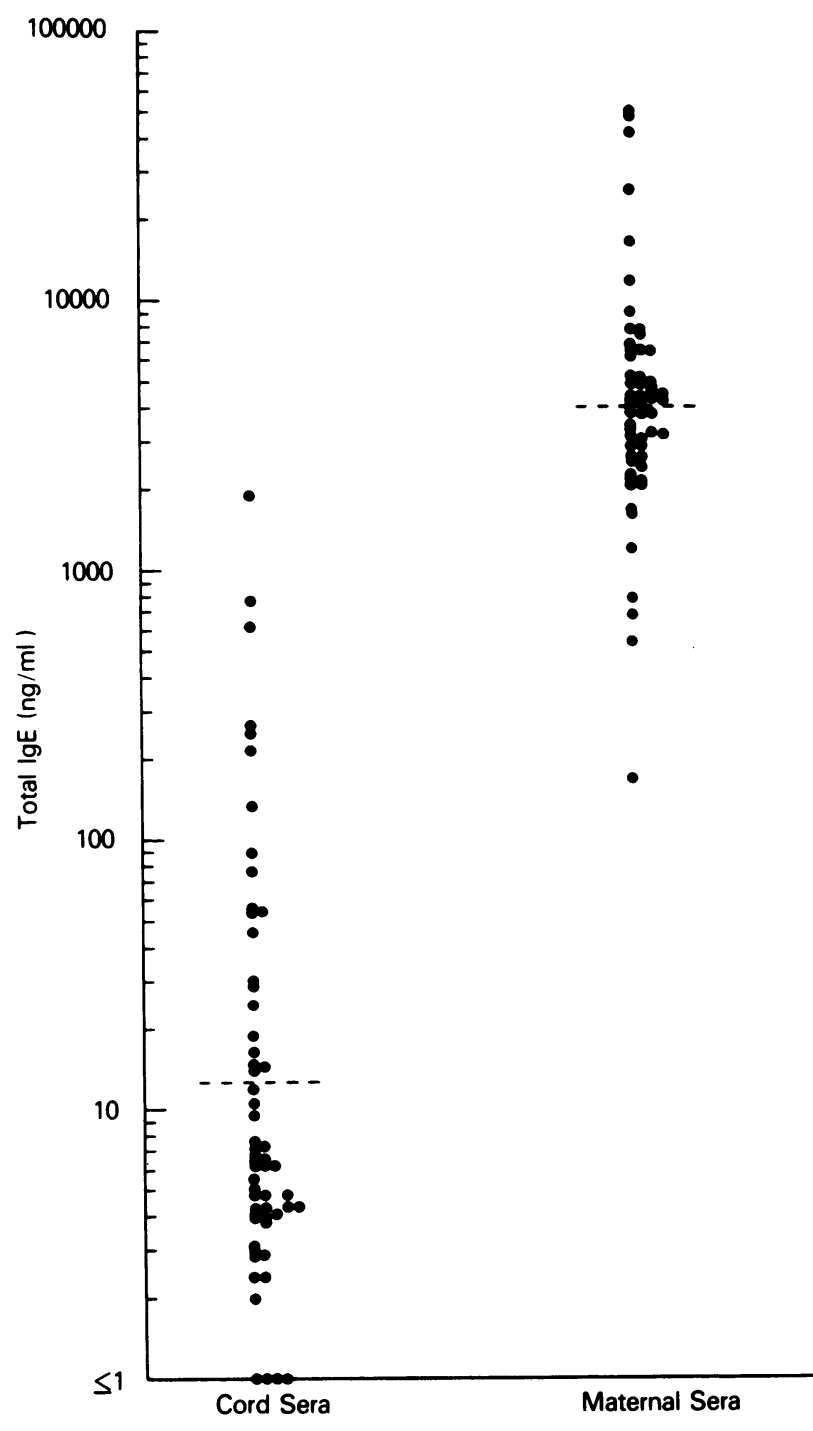

Figure 1 Total serum IgE in cord and maternal sera. Geometric mean for cord sera was $12.6 \mathrm{ng} / \mathrm{ml}$ and for maternal sera, $4,074 \mathrm{ng} / \mathrm{ml}$.

detected in 5 of 57 cord sera. Three of these were borderline elevations $(0.21,0.23$, and $0.25 \mathrm{mg} / \mathrm{ml})$ and two were very high $(1.80$ and $1.10 \mathrm{mg} / \mathrm{ml})$. Three cord sera had IgA levels detectable by radial immunodiffusion $(>0.1 \mathrm{mg} / \mathrm{ml}$ ). Two of these (with $>0.80$ and $0.53 \mathrm{mg} / \mathrm{ml}$ ) were the same sera that contained very high levels of total IgM. The other (with $0.21 \mathrm{mg} / \mathrm{ml}$ $\operatorname{IgA}$ ) was from a serum that contained $0.19 \mathrm{mg} / \mathrm{ml}$ total IgM. The three cord sera with elevated IgA and/ or very high levels of IgM suggesting maternal admixture had the highest cord levels of total IgE (>600 $\mathrm{ng} / \mathrm{ml}$ ) observed and ratios of filaria-specific $\operatorname{IgE}$ to total IgE that were the same as those in paired maternal sera. One of the 14 cord sera with high specific

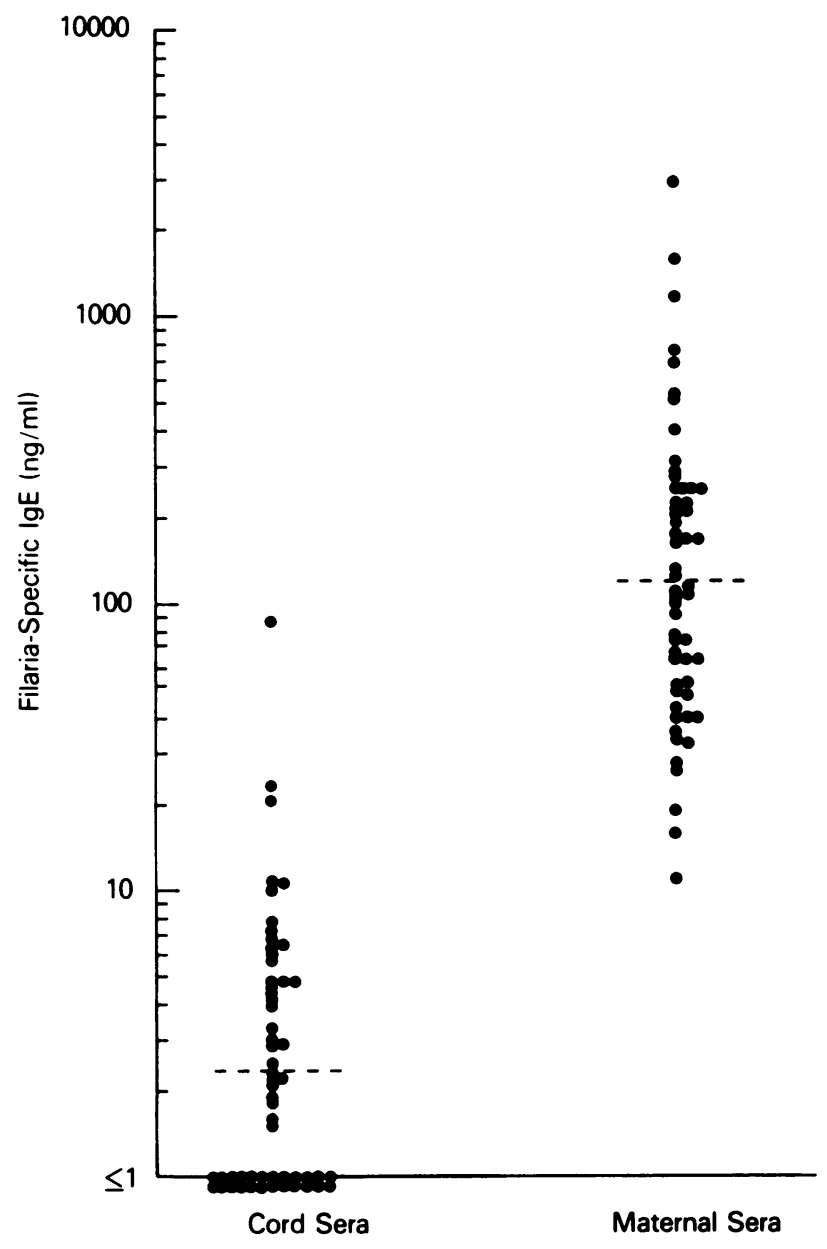

FIGURE 2 Filaria-specific IgE antibody in cord and maternal sera. Geometric mean of cord sera was $2.5 \mathrm{ng} / \mathrm{ml}$ and of maternal sera, $120 \mathrm{ng} / \mathrm{ml}$.

IgE/total IgE ratios had a slightly elevated total IgM level $(0.21 \mathrm{mg} / \mathrm{ml})$. However, the mean IgM for this group of sera $(0.127 \mathrm{mg} / \mathrm{ml}, \mathrm{SE} 0.0045)$ was no greater than the mean IgM for all cord sera $(0.125 \mathrm{mg} / \mathrm{ml}, \mathrm{SE}$ 0.0045 ) after excluding the two sera with very high IgM levels. None of the cord sera with high filariaspecific IgE/total IgE ratios had detectable levels of IgA.

Filaria-specific IgG titers of paired maternal and cord sera were similar, always within one twofold dilution $(r=0.86)$. The only cord sera with detectable filaria-specific IgM were the two sera with very high total IgM and IgA values that suggested maternal blood admixture.

\section{DISCUSSION}

Our results suggest that the human fetus is capable of mounting IgE antibody responses and that such re- 


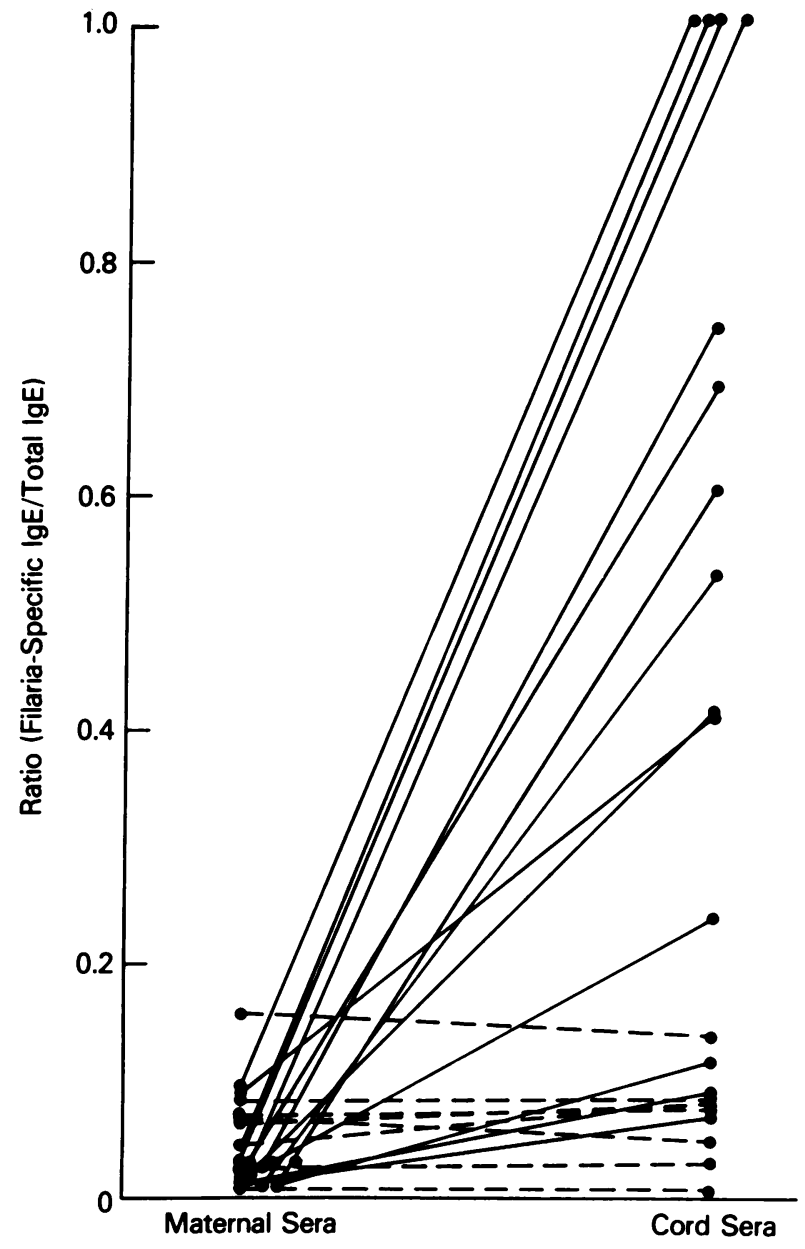

Figure 3 Ratios of filaria-specific IgE to total IgE in maternal-cord serum pairs. Ratios in cord sera were greater than four times the ratios in maternal sera in 14 of 22 serum pairs (solid lines). Cord and maternal ratios were similar in 8 of 22 serum pairs (broken lines).

sponses may occur frequently in the setting of maternal helminth infection. Helminth infections remain a fact of life for most of the world's population (17), but are relatively uncommon in the developed countries where cord blood IgE levels have previously been measured and related to atopic disease. For example, Kjellman et al. $(5,6)$ reported mean cord blood IgE levels of $0.5 \mathrm{ng} / \mathrm{ml}$ in offspring of nonatopic mothers and $2.6 \mathrm{ng} / \mathrm{ml}$ in offspring of atopic mothers. They also noted a statistically significant association between elevated cord blood IgE and the subsequent development of atopic disease in infancy, and similar results were reported by Michel et al. (4). However, the highest cord blood IgE level reported in these three studies was $12 \mathrm{ng} / \mathrm{ml}$, close to the geometric mean of the Indian cord blood results. We have not excluded the

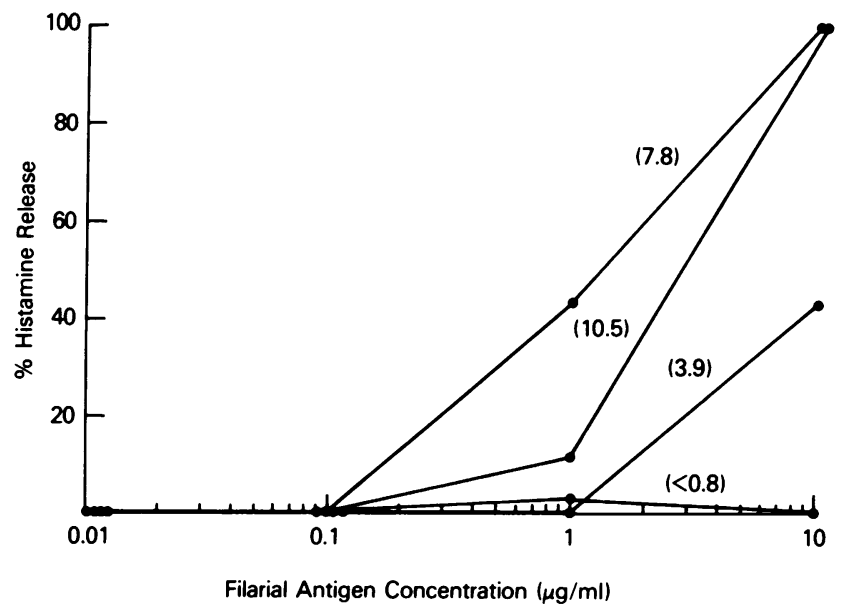

Figure 4 Histamine release of cord blood leukocytes exposed to filarial antigens in vitro. Cord blood filaria-specific IgE values in nanograms per milliliter are shown in parentheses.

possibility that the population studied may have elevated cord blood IgE levels on a genetic basis, but that hypothesis would not explain the parasite-specific IgE antibody present in many cord sera.

The most important question regarding interpretation of the Indian data concerns the origin of the IgE in the cord samples. Studies using radiolabeled erythrocytes have demonstrated that small amounts of blood pass from mother to fetus during labor in $26-70 \%$ of normal deliveries (18-20). The amounts of blood transferred would not necessarily influence cord blood IgM or IgA levels, or IgE levels when mothers have IgE levels within the range normally observed in developed countries. However, mothers in this study had very high total IgE levels and transplacental transfer of as little as $1 \mathrm{ml}$ of blood during labor could significantly alter cord blood IgE measurements. Indeed, we have indirect evidence that this occurred in eight cases where ratios of filaria-specific $\mathrm{IgE}$ to total $\mathrm{IgE}$ in $\mathrm{ma-}$ ternal and cord sera were essentially identical, a finding consistent with leakage. Three of these sera also contained high levels of IgM and/or IgA, further suggesting maternal blood admixture. However, in 14 other cases, the $\operatorname{IgA}, \operatorname{IgM}$, and $\operatorname{IgE}$ ratio data are not consistent with transplacental antibody transfer and suggest that prenatal IgE antibody responses to parasite antigens have occurred. Parasite-specific IgE antibodies would be expected to comprise a greater proportion of total IgE in the sensitized fetus than in the mother because of the relatively limited antigen exposure of the fetus.

One limitation of quantitative RAST assays as used in this study is that they assume similar antibody affinities in the test sera and the standard serum pool. 
This point was discussed and data were presented establishing the validity of the filaria-specific RAST in a previous publication from this laboratory (13). However, for the purposes of the present study, it is worth pointing out that the affinity issue has no bearing on our IgE ratio results that depend on comparisons (relative levels) of specific IgE antibodies within maternalcord serum pairs.

Cord blood IgE antibodies to specific antigens have been reported previously. Kaufman (3) reported a case with skin-sensitizing antibody to mixed grass antigens present at birth and Michel et al. (4) reported three infants with positive RAST tests at birth to milk antigens. Our results are noteworthy because of the frequency of positivity in the population and the fact that these are the first reported prenatal IgE responses to parasite antigens. Mendoza et al. (21) have recently reported that cord blood basophils release histamine when exposed to activated fifth component of complement (C5a), calcium ionophore A23187, and antiIgE antibody (the latter usually required prior passive sensitization of cells with $\operatorname{IgE}$ ). Our results indicate that sensitized cord blood basophils can also undergo antigen-specific histamine release in vitro.

Elevations of total IgE and filaria-specific IgE in cord blood were not confined to offspring of microfilaremic mothers. However, the prevalence of filarial infection in this population almost certainly was higher than the $23 \%$ detected by filtration of a single 1-ml sample of blood. All mothers had detectable filariaspecific IgE antibodies and, conceivably, all may have been infected. In addition, the assay we used to measure filaria-specific IgE is not entirely parasite speciesspecific. Studies from our laboratory have shown that B. malayi antigen cross-reacts significantly with antigens of other filarial species (Onchocerca volvulus, Dipetalonema viteae, and $W$. bancrofti) and lesser degrees of cross-reactivity also exist between $B$. malay $i$ and more distantly related nematodes such as Ascaris lumbricoides (22). Thus, fetal allergic sensitization could occur by transplacental passage of soluble parasite antigens or intact microfilariae (frequently observed in filarial infections of animals and humans (23), or by actual prenatal infection with migrating third-stage larvae of $W$. bancrofti or antigenically related nematodes. Transplacental nematode infections occur commonly in animals (24) and have been reported sporadically in man (25). Whether or not true infection occurs, prenatal exposure to parasite antigen may influence subsequent immune responses of the host to filarial infection and thereby contribute to the extreme variability in disease expression observed in filariasis (26). Support for this view is provided by animal studies that have shown that prenatal immunization can alter postnatal immune responses to infec- tion with the parasitic helminths Schistosoma mansoni and Echinococcus multilocularis $(27,28)$.

Our finding that parasite-specific IgG levels were similar in maternal and cord sera was not surprising in view of the well-recognized equilibration of IgG across the placenta in the third trimester of pregnancy (2). The negative results with respect to total and filaria-specific IgM in cord sera are harder to explain, especially since Dissanayake et al. (29) reported filariaspecific IgM in a small proportion of cord sera from Sri Lanka. However, the issue of transplacental leakage was not addressed in that study and the study was not conducted in a filaria-endemic region. Regarding our negative IgM results, it is possible that the nature of the helminth antigens involved and the mode of antigen presentation to the fetus resulted in isolated $\mathrm{IgE}$ antibody responses or that the IgE responses followed IgM responses that occurred earlier in gestation but which were no longer detectable at birth.

\section{ACKNOWLEDGMENTS}

This study was performed as part of a collaborative project between the Indian Council of Medical Research and the U. S. National Institutes of Health.

\section{REFERENCES}

1. Miller, D. L., T. Hirvonen, and D. Gitlin. 1973. Synthesis of IgE by the human conceptus. J. Allergy Clin. Immunol. 52: 182-188.

2. Alford, C. A., Jr. 1971. Immunoglobulin determinations in the diagnosis of fetal infection. Pediatr. Clin. N. Am. 18: $99-113$.

3. Kaufman, H. S. 1971. Allergy in the newborn: skin test reactions confirmed by the Prausnitz-Kustner test at birth. Clin. Allergy. 71: 363-367.

4. Michel, F. B., J. Bousquet, P. Greillier, M. Robinet-Levy, and Y. Coulomb. 1980. Comparison of cord blood immunoglobulin $\mathrm{E}$ concentrations and maternal allergy for the prediction of atopic diseases in infancy. J. Allergy Clin. Immunol. 65: 422-430.

5. Kjellman, N. I. M., S. G. O. Johansson, and A. Roth. 1976. Serum IgE levels in healthy children quantified by a sandwich technique (PRIST). Clin. Allergy. 6: 5159 .

6. Kjellman, N. I. M., and S. G. O. Johansson. 1976. IgE and atopic allergy in newborns and infants with a family history of atopic disease. Acta Paediatr. Scand. 65: 601607.

7. Ganju, A., P. Baram, and T. Lim. 1979. Serum IgE levels in healthy black American children: a case for environmental influences on IgE. Ann. Allergy. 43: 271-274.

8. Thomas, J., M. A. Abrishami, N. M. Chehreh, and C. S. Walters. 1979. Neonatal IgE values in the black population. Ann. Allergy. 43: 144-145.

9. Katz, D. H. 1980. Recent studies on the regulation of IgE antibody synthesis in experimental animals and man. Immunology. 41: 1-24.

10. Santoro, F., A. Prata, C. N. Castro, and A. Capron. 1980. Circulating antigens, immune complexes, and C3d levels 
in human schistosomiasis: relationship with Schistosoma mansoni egg output. Clin. Exp. Immunol. 42: 219-225.

11. Dennis, D. T., E. McConnell, and G. B. White. 1976. Bancroftian filariasis and membrane filters: are night surveys necessary? Am. J. Trop. Med. Hyg. 25: 257-262.

12. Ottesen, E. A., F. A. Neva, R. S. Paranjape, S. P. Tripathy, K. V. Thiruvengadam, and M. A. Beaven. 1979. Specific allergic sensitization to filarial antigens in tropical eosinophilia syndrome. Lancet. I: 1158-1161.

13. Hussain, R., R. Hamilton, V. Kumaraswami, N. F. Adkinson, and E. Ottesen. 1981. IgE responses in human filariasis. I. Quantitation of filaria-specific IgE. J. Immunol. 127: 1623-1629.

14. Hamilton, R. G., R. Hussain, E. A. Ottesen, and N. F. Adkinson, Jr. 1981. The quantitation of parasite-specific human IgG and IgE in sera: evaluation of solid-phase RIA and ELISA methodology. J. Immunol. Methods. 44: 101-114.

15. Ottesen, E. A., Kumaraswami, R., Paranjape, R. W. Poindexter, and S. P. Tripathy. 1981. Naturally occurring blocking antibodies modulate immediate hypersensitivity responses in human filariasis. J. Immunol. 127: 2014-2020.

16. Beaven, M. A., S. Jacobsen, and Z. Horakova. 1971. Modification of the enzymatic isotopic assay of histamine and its application to measurement of histamine in tissue, serum, and urine. Clin. Chim. Acta. 37: 91-103.

17. Stoll, N. 1947. This wormy world. J. Parasitol. 33: 118.

18. Zarou, D. M., H. C. Lightman, and L. M. Hellman. 1964 The transmission of chromium 51 tagged maternal erythrocytes from mother to fetus. Am. J. Obstet. Gynecol. 88: 565-571.

19. Elmer, H. 1972. Untersuchungen zur maternofetalen
Transfusion bei geburtshilflichen Operationen. Geburtsh. Frauenheilkd. 32: 657-661.

20. Smith, K., J. L. Duhring, J. W. Greene, Jr., D. B. Rochlin, and W. Blakemore. 1961. Transfer of maternal erythrocytes across the human placenta. Obstet. Gynecol. 18: 673-676.

21. Mendosa, G. R., K. Minagawa, F. Orner, and E. R. Stiehm. 1982. Basophil releasability in the newborn: factors limiting immunoglobulin E-mediated histamine release. Pediatrics. 69: 188-192.

22. Weiss, N., R. Hussain, and E. A. Ottesen. 1982. IgE antibodies are more species-specific than IgG antibodies in human onchocerciasis and lymphatic filariasis. Immunology. 45: 129-137.

23. Raghaven, N. G. S. 1958. Congenital filariasis. Bull. Natl. Soc. Ind. Mal. Mosq. Dis. 6: 147-154.

24. Miller, G. C. 1981. Helminths and the transmammary route of infection. Parasitology. 82: 335-342.

25. Cort, W. W. 1921. Prenatal infestation with parasitic worms. JAMA (J. Am. Med. Assoc.). 76: 170-171.

26. Ottesen, E. A. 1980. Immunopathology of lymphatic filariasis in man. Springer Semin. Immunopathol. 2: 373-385.

27. Lewert, R., and S. Mandlowitz. 1969. Schistosomiasis: prenatal induction of tolerance to antigens. Nature (Lond.). 224: 1029-1030.

28. Hinz, E., and S. Domm. 1980. Die experimentelle Echinococcus multilocularis infection von Muttermaeusen und ihre Bedeutung fuer die Nachkommen. Tropenmed. Parasitol. 31: 1235-1242.

29. Dissanayake, S., L. V. K. deSilva, and M. M. Ismail 1980. IgM antibody to filarial antigens in human cord blood: possibility of transplacental infection. Trans. R. Soc. Trop. Med. Hyg. 74: 542-544. 